\title{
A COR VERDE DO ENDOSPERMA DO CAFÉ (1)
}

\author{
PAULO MAZZAFERA (2), OLIVEIRO GUERREIRO FILHO (3) e ALCIDES CARVALHO $(3,4)$
}

\begin{abstract}
RESUMO
Realizaram-se comparaçōes entre as sementes dos cultivares Mundo Novo de Coffea arabica, cujo endosperma é verde, com as do cultivar Cera, dessa espécie, de endosperma amarelo, com o objetivo de determinar os componentes responsáveis por aquela cor. Nas análises de clorofilas, flavonóides, diterpenos totais, ácido clorogênico e ions $\mathrm{Mg}, \mathrm{Ca}, \mathrm{K}, \mathrm{Fe} e$ $B$, nenhuma diferença foi verificada entre os dois cultivares, sugerindo que a coloração verde se deva à presença de outros componentes ou que o 'Cera' apresente um componente que não ocorre no 'Mundo Novo' e que inibe o desenvolvimento da cor verde no seu endosperma.
\end{abstract}

Termos de indexação: Coffea arabica, cultivares Mundo Novo e Cera, flavonóides, diterpenos, ácido clorogênico, clorofila, íns.

\section{INTRODUÇÃO}

O endosperma da semente de café (Coffea arabica L.) em geral apresenta coloração verde cuja intensidade parece refletir os cuidados dispensados no processamento dos frutos maduros após a colheita. Estudos foram feitos correlacionando a cor verde-azulada do endosperma com a qualidade da bebida (BACCHI, 1962; NORTHMORE, 1966; AMORIM \& SILVA, 1968; TEIXEIRA et al., 1977; MELO et al., 1980).

(1) Recebido para publicação em 19 de julho e aceito em 13 de outubro de 1988.

(2) Departamento de Fisiologia Vegetal, Unicamp. pinas (SP).

(3) Seçāo de Genética, Instituto Agronômico de Campinas (IAC), Caixa Postal 28, 13001 Cam-

(4) Com bolsa de pesquisa do CNPq. 
NORTHMORE (1968) conseguiu reproduzir em extratos aquosos de sementes de café as cores que ocorrem durante o seu envelhecimento. Concluiu que o ácido clorogênico e o ín $\mathrm{Mg}$ formariam um complexo que, sob determinadas faixas de $\mathrm{pH}$, poderia originar a coloração azul-esverdeada do café de boa qualidade do Quênia. Extratos aquosos alcalinizados desenvolviam as cores verde, azul e marrom, à medida que se tornavam ácidos: na primeira coloração, a maior absorçāo de luz se dava em $660 \mathrm{~nm}$ e, à medida que havia mudança de cor, passava a absorver mais em $600 \mathrm{~nm}$. A acidificaçāo dos extratos a pH 3,5 ocasionava a formaçāo de um precipitado azul, cujo espectro em UV era semelhante ao do ácido clorogênico. Nesse precipitado, detectou-se a presença dos íons $\mathrm{Fe}, \mathrm{Mg}$, $\mathrm{Si}, \mathrm{Al}$ e $\mathrm{B}$. Entretanto, à primeira impressão, o ácido clorogênico parece não ser o responsável pela cor verde do café, pois o cultivar Cera de $C$. arabica, que produz sementes com endosperma amarelo (CARVALHO \& KRUG, 1949), apresenta teores até um pouco mais elevados desse ácido do que outros cultivares com sementes verdes; apresenta, ainda, bebida de boa qualidade (CARELLI et al., 1974).

Outras substâncias têm sido relacionadas como possiveis determinantes da cor verde do café. GIBSON (1971) demonstrou que, durante a secagem do café ao sol, havia formação de alcoóis diterpênicos, os quais nāo eram observados antes desse processo ou quando secos crioscopicamente. A polimerização de uma dessas substâncias, o cafestol, originaria a cor amarela, que passaria ao marrom na presença do oxigênio. A polimerização do outro diterpeno, o kahweol, originaria pigmentos azul-esverdeados. Concluiu que a cor do endosperma do café seria produto da formaçāo de ésteres de kahweol e cafestol.

Apesar da existência de vários trabalhos relacionados à identificação da substância responsável pela cor verde do café, nenhuma análise comparativa foi realizada entre o café de endosperma de cor verde e outro com endosperma de cor diferente e possuindo bebida de boa qualidade. Neste trabalho são relatados os resultados das análises comparativas de flavonóides, clorofilas, diterpenos, ions $\mathrm{Mg}, \mathrm{Ca}, \mathrm{K}, \mathrm{Fe}$ e B, e alterações nas cores de extratos aquosos em função do $\mathrm{pH}$, do endosperma verde e amarelo de sementes dos cultivares Mundo Novo e Cera respectivamente.

\section{MATERIAL E MÉTODOS}

\subsection{Material vegetal}

As sementes utilizadas para estudo originaram-se de frutos recém-colhidos dos cultivares Mundo Novo e Cera de $C$. arabica. O pergaminho (endocarpo) foi retirado manualmente e a película prateada (integumento), por fricção com paro umedecido. As sementes foram postas a secar por uma semana em estufa a $70^{\circ} \mathrm{C}$ e moídas à granulometria de 60 mesh. 


\subsection{Flavonóides}

As sementes moídas de café foram desengorduradas por 24 horas em Soxhlet com éter de petróleo $30-60^{\circ} \mathrm{C}$ e, a partir de $2 \mathrm{~g}$, fez-se a extração de flavonóides com etanol $80 \%$ sob refluxo, por 90 minutos. O extrato obtido foi reduzido de volume em evaporador rotatório a $40^{\circ} \mathrm{C}$ e cromatografado bidimensionalmente em placas delgadas de celulose (HARBORNE, 1973; SWAIN, 1965), empregando-se butanol:ácido acético:água (6:2:1) e ácido acético 2\% (SEIKEL, 1962). Os cromatogramas foram visualizados sob luz visivel e ultravioleta, com e sem vapores de amônia, e revelados com solução aquosa de $\mathrm{Na}_{2} \mathrm{CO}_{3}$ e solução etanólica de $\mathrm{AlCl}_{3}$, com posterior obsenação em ultravioleta (RIBEREAU-GAYON, 1972; SEIKEL, 1962).

\subsection{Clorofilas}

Imergiram-se $3 \mathrm{~g}$ de sementes com $13 \%$ de umidade em $5 \mathrm{ml}$ de acetona $80 \%$ por dez minutos no escuro, macerando-as em graal. O extrato foi filtrado e $o$ material retido, lavado com $15 \mathrm{ml}$ de solvente e novamente filtrado. Nos extratos combinados, efetuaram-se leituras de absorbância em 645 e $663 \mathrm{~nm}$ e aplicaram-se os resultados nas fórmulas propostas por ARNON (1949), para determinaçāo de clorofila total e clorofilas a e b.

\subsection{Diterpenos}

Os principais componentes da matéria insaponificável dos grãos de café são os diterpenos kahweol e cafestol (HARTMAN et al., 1968), podendo corresponder a até 18,5\% do óleo total (Kaufman \& Hansagar, 1962, apud HARTMAN et al., 1968). Dessa maneira, pela metodologia empregada (WURZIGER \& SUCHE, 1983), determinou-se o coeficiente de extinção da matéria insaponificável das sementes de café. As sementes moídas foram tratadas com éter de petróleo $30-60^{\circ} \mathrm{C}$ em Soxhlet por duas horas e o solvente, removido em evaporador rotatório a $30^{\circ} \mathrm{C}$. A $1 \mathrm{ml}$ do extrato obtido, adicionaram-se $2 \mathrm{ml}$ de solução de $\mathrm{KOH}$ aquosa/alcoólica (uma parte de $\mathrm{KOH} 10 \%$ aquoso + uma parte de etanol $99,5 \%$ ), seguindo-se agitação por 15 minutos e repouso por 30 minutos. Da fase superior, tomou-se $0,5 \mathrm{ml}$, acrescentando-se-lhe $2 \mathrm{ml}$ de ácido acético e $0,1 \mathrm{ml}$ de solução de $\mathrm{KI}$ saturada ( $144 \mathrm{~g} / 100 \mathrm{ml})$, permanecendo a mistura por 12 minutos em banho-maria a $70^{\circ} \mathrm{C}$. Fez-se a leitura de absorbância em $630 \mathrm{~nm}$, utilizando-se ácido acético como branco.

\subsection{Extratos aquosos}

Praticamente, todos os passos aqui realizados foram os mesmos adotados por NORTHMORE (1968). Amostras de café moído foram desengorduradas em Soxhlet por 24 horas com éter de petróleo $30-60^{\circ} \mathrm{C}$. Um grama do material foi extraído por filtração com $100 \mathrm{ml}$ de água fervente em funil sob pressão. $O$ extrato 
obtido foi clarificado por centrifugação a $2.000 \mathrm{rpm}$ por 15 minutos, alcalinizado a $\mathrm{pH} 8,0 \mathrm{com} \mathrm{NH} \mathrm{NH}_{4} \mathrm{OH}, 1 \mathrm{M}$ e deixado em repouso por oito horas. A diferentes intervalos de tempo, fez-se o espectro de absorção de luz dos extratos. Outros extratos, após alcalinizados, foram acidificados com $\mathrm{HCl} 0,1 \mathrm{M}$ a pH 5,5 ou $3,5 \mathrm{ou}$, ainda, alcalinizados a pH 8,3, 8,7 e 9,1, e deixados em repouso por cerca de 32 horas. Em outros extratos, alcalinizados a pH 8,7, estudou-se o efeito da adição do ion $\mathrm{Mg}$, na forma de $\mathrm{MgSO}_{4}(0,05 \mathrm{~g} / 100 \mathrm{ml})$, e o efeito da luz na presença ou não do mesmo ion, pela exposição por 1,5 hora ao sol.

\subsection{Análise de ions}

As análises para $\mathrm{Ca}, \mathrm{Mg}, \mathrm{K}, \mathrm{Fe}$ e $\mathrm{B}$ foram realizadas pela Seçāo de Fertilidade do Solo e Nutrição de Plantas do Instituto Agronômico de Campinas.

\section{RESULTADOS}

\subsection{Flavonóides, clorofilas e diterpenos}

O quadro 1 apresenta os valores dos Rfs e as prováveis classes de flavonóides a que pertencem as substâncias separadas por cromatografia, e a figura 1 indica a posição das manchas nos cromatogramas. O quadro 2 traz os valores de clorofila total, clorofilas a e b e diterpenos. Tanto para flavonóides como para clorofilas, não se observaram diferenças entre os dois tipos de café. Também para diterpenos nāo se constataram diferenças estatisticamente significativas, sendo as absorbâncias em Mundo Novo e Cera de 0,118 e 0,130 respectivamente (Quadro 2).

\subsection{Extratos aquosos}

Após a alcalinização a pH 8,0, os extratos adquiriram a cor amarela, aparecendo a cor verde depois do repouso de oito horas. A maior absorbância nos extratos verdes deu-se em $670 \mathrm{~nm}$, apresentando o cultivar Cera o valor de 0,966 e o 'Mundo Novo', 0,823, na média de seis repetiçōes. A acidificação dos extratos a pH 5,0 levou à formação de cor verde mais intensa do que os extratos com pH 8,0 deixados em repouso por oito horas. Houve inicio de formação de um precipitado azul, com decréscimo na absorção de luz em 670nm e acréscimo em $620 \mathrm{~nm}$. Nos extratos com pH 3,5, notou-se formação mais acentuada do precipitado, tornando-se o sobrenadante amarelado. Alguns dos extratos a pH 5,0 foram deixados em repouso, notando-se que havia continuidade na formação do precipitado e que, posteriormente, o verde passava a marrom e, em seguida, a amarelo-claro, como nos extratos acidificados a pH 3,5. A maior absorbância, nesta última coloração, ocorreu em 360nm. 
QUADRO 1. Valores dos Ris das manchas identificadas nos cromatogramas dos extratos etanólicos do endosperma verde de sementes do cultivar Mundo Novo e do endosperma amarelo de sementes do cultivar Cera de Coffea arabica, e prováveis classes do flavonóide a que pertencem as substancias separadas

\begin{tabular}{lccccc}
\hline \multirow{2}{*}{$\begin{array}{c}\text { Número } \\
\text { da mancha }\end{array}$} & $\begin{array}{c}\text { Sementes verdes } \\
\text { (Mundo Novo) }\end{array}$ & $\begin{array}{c}\text { Sementes amarelas } \\
\text { (Cera) }\end{array}$ & $\begin{array}{c}\text { Classe } \\
\text { do flavonóide }\end{array}$ \\
\cline { 2 - 5 } & B.A.A. & Ac. $2 \%$ & B.A.A. & Ac. $2 \%$ & \\
1 & 0,59 & 0,41 & 0,59 & 0,39 & Flavonol \\
2 & 0,68 & 0,50 & 0,68 & 0,46 & Flavonol \\
3 & 0,91 & 0,70 & 0,96 & 0,67 & Flavonol (?) \\
4 & 0,28 & 0,91 & 0,27 & 0,90 & (?) \\
5 & 0,55 & 0,59 & 0,52 & 0,57 & Flavonol \\
6 & 0,79 & 0,52 & 0,78 & 0,52 & Flavonol (?) \\
7 & 0,86 & 0,02 & 0,89 & 0,02 & Flavonol \\
8 & 0,73 & 0,75 & 0,70 & 0,76 & Flavonol \\
9 & 0,86 & 0,76 & 0,81 & 0,75 & Flavonol \\
\hline
\end{tabular}

(1) B.A.A. = butanol:ácido acético: água (6:2:1). Ac. $2 \%$ = ácido acético $2 \%$. (?) = Classe não identificada.

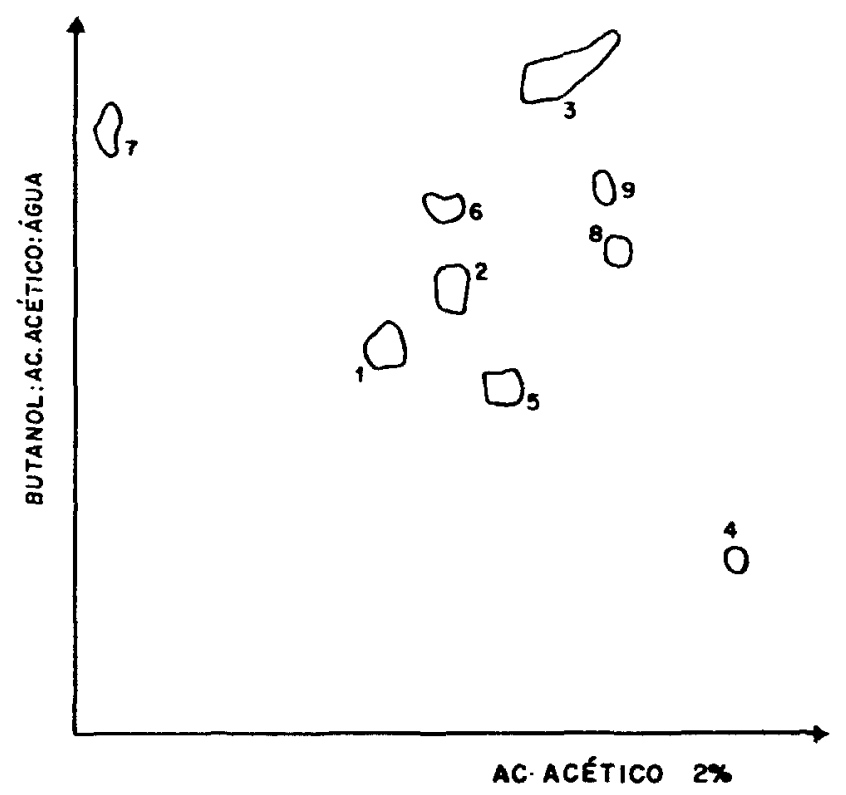

FIGURA 1. Representação de flavonóides nos cromatogramas dos extratos etanólicos de sementes dos cultivares Mundo Novo e Cera de $C$. arabica. 
Dos extratos a pH 3,5, os precipitados foram separados por centrifugaçāo e secos em estufa a $70^{\circ} \mathrm{C}$. Feitas suas pesagens, não foram observadas diferenças entre o 'Cera' $(0,0654 \mathrm{~g} / \mathrm{g}$ de café) e 'Mundo Novo' (0,0659g/g de café). Adicionalmente, com a finalidade de verificar a influência do ácido clorogênico, empregou-se o método descrito por AMORIM et al. (1973), sendo feitas apenas as leituras de absorbância após a extração. $O$ 'Cera' apresentou valor médio de seis repetiçōes de 0,969 e o 'Mundo Novo', de 0,861, confirmando os dados de CARELLI et al. (1974).

QUADRO 2. Diterpenos, clorofila total e clorofilas a e b em sementes dos cultivares Mundo Novo e Cera de Coffea arabica

\begin{tabular}{lcccc}
\hline \multirow{2}{*}{ Cultivares } & \multicolumn{3}{c}{ Clorofilas (1) } & Diterpenos (2) \\
\cline { 2 - 5 } & Total & $\mathrm{a}$ & $\mathrm{b}$ & \\
\hline Mundo Novo & $\mathrm{g} / \mathrm{g}$ & $\mathrm{g} / \mathrm{g}$ & $\mathrm{g} / \mathrm{g}$ & Absorbância ( $\left.{ }^{3}\right)$ \\
Cera & 0,0045 & 0,0034 & 0,0011 & 0,118 \\
& 0,0044 & 0,0034 & 0,0010 & 0,130 \\
\hline
\end{tabular}

(1) Média de três repetiçōes. (2) Média de quatro repetiçōes. (3) Em 630nm.

No quadro 3 , encontram-se os dados referentes à influência do $\mathrm{pH}$ no desenvolvimento de cores nos extratos de ambos os cultivares. Dependendo do $\mathrm{pH}$, o aparecimento da cor azul ou marrom revelou-se diferente para os dois: para o 'Cera', houve manutenção da cor azul no pH próximo a 8,3, enquanto, para 0 'Mundo Novo', isso ocorreu em pH 8,7. Pelo tempo de repouso, houve maior diferença entre o pH inicial e o final nos extratos que desenvolveram a cor marrom. À medida que houve passagem do verde para o marrom, a absorbância em $670 \mathrm{~nm}$ diminuiu.

A figura 2 representa a influência do $\mathrm{Mg}$ no desenvolvimento de cores em extratos do 'Mundo Novo' e 'Cera' alcalinizados a pH 8,7. Observa-se que a queda na absorção de luz em $670 \mathrm{~nm}$ foi menos intensa nos extratos que continham $\mathrm{Mg}$, em comparação com aqueles com ausência desse ion. Nas amostras com esse ion, a coloração inicial era de um verde mais claro e vivo do que os extratos sem Mg.

A figura 3 apresenta os dados de extratos com e sem Mg que foram expostos à luz solar por 1,5 hora. Esse intervalo provocou uma queda na absorbância dos extratos; os que continham $\mathrm{Mg}$ apresentaram uma coloração esverdeada mais intensa, absorvendo mais em $670 \mathrm{~nm}$. 
QUADRO 3. Influência do $\mathrm{pH}$ no desenvolvimento de cores em extratos aquosos do endosperma de sementes dos cultivares Mundo Novo e Cera de $C$. arabica, após período de repouso ( $\left.{ }^{1}\right)$

\begin{tabular}{|c|c|c|c|c|c|c|c|}
\hline \multirow{2}{*}{ Cultivares } & \multicolumn{2}{|c|}{$\mathrm{pH}$} & \multirow{2}{*}{$\Delta p H$} & \multicolumn{2}{|c|}{ Absorbância $670 \mathrm{~nm}$} & \multirow{2}{*}{$\Delta \mathrm{t}$} & \multirow{2}{*}{$\begin{array}{l}\text { Cor } \\
\text { final (2) }\end{array}$} \\
\hline & Inicial & Final & & Inicial & Final & & \\
\hline
\end{tabular}

\begin{tabular}{llllllll} 
Mundo Novo & 8,38 & 5,82 & 2,56 & 0,449 & 1,280 & 31,53 & Marrom \\
& 8,69 & 7,27 & 1,42 & 0,482 & 1,561 & 31,42 & Azul \\
& 9,08 & 6,28 & 2,81 & 0,678 & 1,699 & 31,37 & Azul/marrom \\
\multirow{3}{*}{ Cera } & & & & & & & \\
& 8,31 & 7,02 & 1,29 & 0,187 & 0,870 & 31,35 & Azul \\
& 8,71 & 6,45 & 2,26 & 0,482 & 1,426 & 31,22 & Azul/marrom \\
& 9,07 & 6,71 & 2,36 & 0,699 & 1,957 & 31,13 & Azul/marrom
\end{tabular}

(1) Média de três repetiçōes.

(2) Azul/marrom = mudando do azul para o marrom.
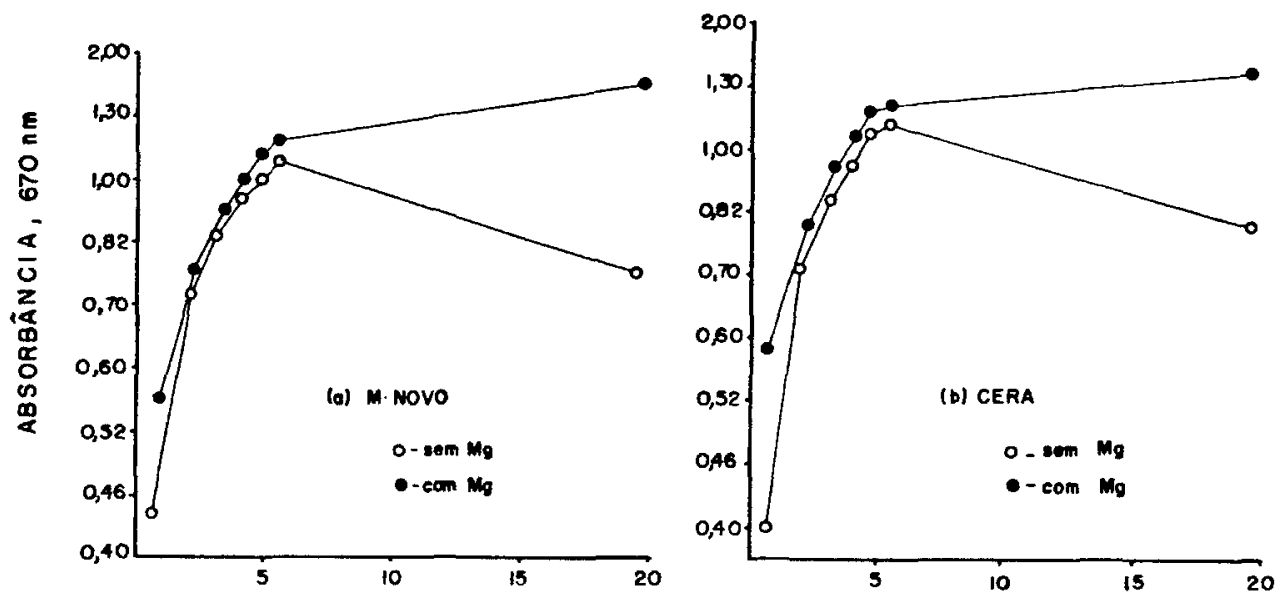

TEMPO, horas

FIGURA 2. Efeito do Mg na absorção de luz, no comprimento de onda de $670 \mathrm{~nm}$, em extratos aquosos $\mathrm{pH} \mathrm{8,7}$ de sementes dos cultivares (a) Mundo Novo e (b) Cera de $C$. arabica. 


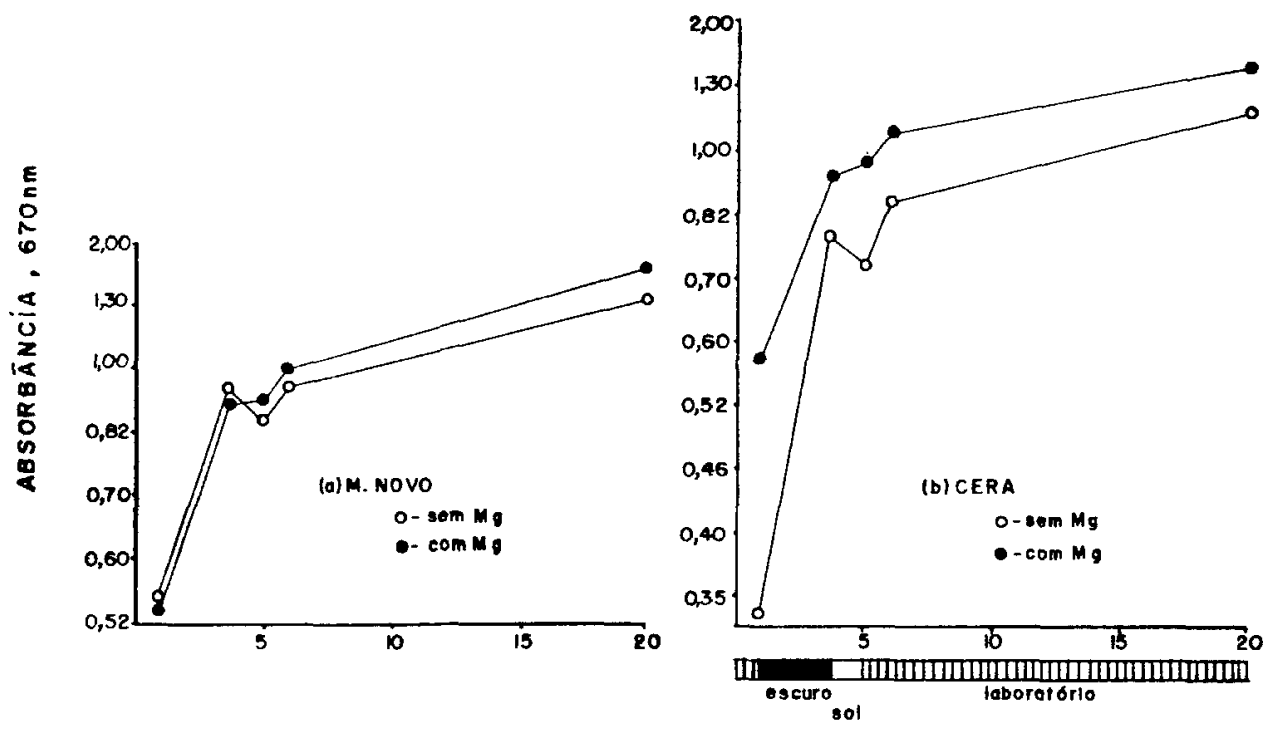

TEMPO, horas

FIGURA 3. Efeito da luz solar na absorçăo de luz, no comprimento de onda de $670 \mathrm{~nm}$, em extratos aquosos $\mathrm{pH} \mathrm{8,7,} \mathrm{com} \mathrm{e} \mathrm{sem} \mathrm{Mg}$, de sementes dos cultivares (a) Mundo Novo e (b) Cera de C. arabica.

\section{3. ions}

No quadro 4 encontram-se os dados referentes ao conteúdo dos ions $K$, $\mathrm{Ca}, \mathrm{Mg}, \mathrm{Fe}$ e $\mathrm{B}$ nas sementes dos cultivares Mundo Novo e Cera. Para o K, o 'Mundo Novo' apresentou valor maior, ocorrendo o inverso em relação ao $\mathrm{Fe}$. Quanto aos ions $\mathrm{Mg}, \mathrm{Ca}$ e $\mathrm{B}$, não houve diferenças entre ambos.

QUADRO 4. Conteúdo de $\mathrm{K}, \mathrm{Mg}, \mathrm{Ca}, \mathrm{Fe}$ e $\mathrm{B}$ no endosperma de sementes dos cultivares Mundo Novo e Cera de C. arabica (1)

\begin{tabular}{lccccc}
\hline Cultivares (2) & $\mathrm{K}$ & $\mathrm{Ca}$ & $\mathrm{Mg}$ & $\mathrm{Fe}$ & $\mathrm{B}$ \\
\hline & $\%$ & $\%$ & $\%$ & $\mathrm{ppm}$ & $\mathrm{ppm}$ \\
Mundo Novo & $1,64 \mathrm{a}$ & $0,13 \mathrm{a}$ & $0,19 \mathrm{a}$ & $33 \mathrm{~b}$ & $10 \mathrm{a}$ \\
Cera & $1,51 \mathrm{~b}$ & $0,14 \mathrm{a}$ & $0,18 \mathrm{a}$ & $39 \mathrm{a}$ & $10 \mathrm{a}$ \\
\hline
\end{tabular}

(1) Média de três repetiçóes. (2) Médias seguidas de letras diferentes indicam significância pelo teste de Tukey a $5 \%$. 


\section{DISCUSSÃO}

De acordo com os resultados obtidos, seria possivel afirmar, a princípio, que os flavonóides, as clorofilas, o ácido clorogênico, o precipitado azul, os íns e os diterpenos kahweol e cafestol, isoladamente, não seriam os responsáveis pela cor verde do endosperma do café. No entanto, cada caso deve ser especialmente considerado.

Em tecidos vegetais, os flavonóides são conhecidos como substâncias que podem conferir diferentes colorações; em sua maioria, porém, limitam-se àquelas que nāo o verde, como o amarelo, vermelho e azul (HARBORNE, 1965). Assim, o estudo dessas substâncias foi feito com a intenção de excluir a alternativa, o que foi comprovado pelos resultados obtidos.

Quanto às clorofilas, não se constataram diferenças entre os dois cultivares. GIBSON (1971) observou que a pelicula prateada contém clorofilas. Assim, os valores encontrados podem ser devidos a resíduos desse tecido, que ficaram aderidos à ranhura central do ventre das sementes. De qualquer forma, estas substâncias não parecem ser responsáveis pela cor verde do café.

Apesar de a determinação de diterpenos não ter evidenciado diferenças entre os cultivares Cera e Mundo Novo, seria razoável supor que a proporção entre cafestol e kahweol pudesse influenciar na determinação da cor dos dois tipos de café estudados. No entanto, o kahweol, composto que tem merecido maior atenção como participante na formação da cor do café (GIBSON, 1971), não é encontrado no endosperma de cor verde do cultivar Robusta de $C$. canephora (WURZIGER \& SUCHE, 1983).

Segundo NORTHMORE (1968), tanto a coloração como o precipitado azul formado na acidificação de extratos aquosos estariam relacionados com a formação do ácido virídico, produto da oxidação do ácido clorogênico em solução alcalina. $\mathrm{O}$ efeito do ion $\mathrm{Mg}$ no desenvolvimento da cor azul seria estabilizar essa oxidação, formando o complexo azul. No entanto, com os dados obtidos sobre o ácido clorogênico, confirmando aqueles de CARELLI et al. (1974), é pouco provável que esta substância, isoladamente, seja responsável pela cor do café.

Outros estudos demonstraram que, pela combinação do ion Fe com o ácido clorogênico, podem-se obter soluções de coloração verde, porém insensíveis à luz (NORTHMORE, 1966). O Fe poderia desempenhar algum papel na formação da cor verde do endosperma do café, pois cafeeiros deficientes nesse elemento produzem sementes com endosperma âmbar (ROBINSON, 1960). Evidências de que outros íons, como $\mathrm{K}$ e $\mathrm{Ca}$, poderiam afetar a cor do endosperma do café foram obtidas por NORTHMORE (1965), segundo o qual sementes com excesso desses dois elementos tendem a apresentar endosperma de coloração marrom. 
Pelas análises dos ions, realizadas nos cultivares Cera e Mundo Novo, pôde-se notar que o primeiro apresentou mais $\mathrm{Fe}$ e menos $\mathrm{K}$, nāo diferindo em relação aos íons $\mathrm{Ca}, \mathrm{Mg}$ e $\mathrm{B}$. Apesar de NORTHMORE (1968) ter detectado a presença de $\mathrm{Mg}$, Fe e $\mathrm{B}$ no precipitado azul de extratos aquosos acidificados, relacionando-a com a cor da semente de café, não se acredita que a análise de íns no mesmo poderia diferenciar os dois cultivares de café estudados, pelo simples fato de que tal precipitado foi encontrado tanto no 'Cera' como no 'Mundo Novo'.

NORTHMORE (1968) mostrou que as alteraçōes na coloração de extratos aquosos de café ocorriam em funçāo do $\mathrm{pH}$, sendo que, em um período superior a 20 horas, o pH 8,7 foi o mais favorável para o desenvolvimento da cor azul. Em faixas inferiores de $\mathrm{pH}$, não havia a formação dessa cor, permanecendo os extratos verdes. No presente estudo, confirmou-se a influência do $\mathrm{pH}$ no desenvolvimento de coloração, porém o melhor desenvolvimento de cor no 'Cera' ocorreu em pH próximo a 8,3 e, no 'Mundo Novo', próximo a 8,7. Constatou-se, também, que a diferença entre o pH inicial e o final foi maior nos pHs 8,7 e 9,1 para o 'Cera' e 8,3 e 9,1 para o 'Mundo Novo' e que, à medida que houve a passagem do verde para a azul, a absorbância diminuiu em $670 \mathrm{~nm}$ e aumentou em $620 \mathrm{~nm}$.

Não se conhece, no entanto, uma explicação para essas variações quanto à velocidade de desenvolvimento de cores e diferenças de $\mathrm{pH}$, entre os dois cultivares, nem o motivo de os picos de absorção de luz se situarem em tais valores, quando NORTHMORE (1968) determinou valores de 660 e $600 \mathrm{~nm}$. De qualquer forma, a seqüência de formação de cores foi a mesma no "Mundo Novo' e no 'Cera', do mesmo modo que o comportamento dos extratos, quando testados quanto ao efeito da luz e do ion $\mathrm{Mg}$, mostrando que, se tais efeitos são devidos à substância que confere a cor verde ao endosperma das sementes do 'Mundo Novo', ela está presente no 'Cera'.

Estudos mais recentes (Guyot et al., 1987, apud CHASSEVENT, 1987) indicaram ser um pigmento azul o responsável pela cor verde do café, resultante da reação entre a quinona formada a partir do ácido caféico, ou de seus ésteres, com o grupamento $\alpha$-amino de aminoácidos. Essa cor seria produto da mistura do azul, formado por essa substância, com o amarelo do excesso de quinonas. $\mathrm{O} p H$ e a atividade da polifenoloxidase teriam papel na formação do pigmento e na sua estabilidade, assim como este seria fotossensivel e instável a temperaturas superiores a $35^{\circ} \mathrm{C}$.

Algumas informaçōes que poderiam estar relacionadas com essa hipótese devem ser citadas. MELO et al. (1980) observaram que sementes verdes, que se tornaram esbranquiçadas com o decorrer do tempo, apresentavam maior teor em aminoácidos, e BASSO et al. (1979) notaram que o cultivar Cera apresentava um conteúdo em poliaminas, produtos da degradação de aminoácidos, maior do que o 'Mundo Novo'. Ainda, da degradação do ácido clorogênico (ácido 3-cafeoilquínico) são formados ácido caféico e ácido quínico (SMITH, 1963). 
A formação de quinonas, segundo AMORIM \& SILVA (1968), está relacionada com a atividade da polifenoloxidase, que é maior em café de coloração verde de boa qualidade (MELO et al., 1980). Complementando, o teor de fenóis solúveis é praticamente o mesmo em cafés de diferentes qualidades (AMORIM et al., 1974).

Com exceção do presente trabalho, em nenhum outro fez-se uma comparação entre cultivares com endosperma de cor verde e de cor amarela, como a do 'Cera'. Como não se notaram diferenças nos compostos analisados, pode-se supor que a cor verde não seja devida a esses componentes, tendo como padrão de comparação sementes do 'Cera', ou que este cafeeiro possua um composto que inibe o desenvolvimento da cor verde. Estudos posteriores poderão elucidar essa questão, bem como a mudança de coloração do endosperma à medida que a semente envelhece.

\section{SUMMARY}

\section{ON THE GREEN COLOR OF COFFEE ENDOSPERM}

A comparison was made between the green seeded Mundo Novo and the yellow seeded Cera cultivars of Coffea arabica, in order to determine the components responsible for the green color of the endosperm. Both cultivars produce beverage of good quality. Chlorophylls, flavonoids, total diterpens, chlorogenic acid, and $\mathrm{K}, \mathrm{Ca}, \mathrm{Mg}, \mathrm{Fe}$ and $\mathrm{B}$ ions were determined in beans of both cultivars. No differences between cultivars were found on these component contents, what suggests that the green color may be due to other compounds or that the Cera endosperm may have an inhibitor component of the green color of the cofee beans.

Index terms: Coffea arabica, cultivars Mundo Novo and Cera, flavonoids, diterpens, chlorogenic acid, chlorophyll, ions.

\section{REFERÊNCIAS BIBLIOGRÁFICAS}

AMORIM, H.V.; GUÉRCIO, M.A.; CORTEZ, J.G. \& MALAVOLTA, E. Métodos de análise orgânica em café. I. Comparação entre métodos de determinação de ácido clorogênico. Anais da Escola Superior de Agricultura "Luiz de Queiroz", Piracicaba, 30:281-291, 1973.

\& SILVA, D.M. Relationship between the polyphenoloxidase activity of coffee beans and the quality of coffee beverage. Nature, London, 219(5152):381, 1968.

; TEIXEIRA, A.A.; GUÉRCIO, M.A.; CRUZ, V.F. \& MALAVOLTA, E. Chemistry of brazilian green coffee and the quality of beverage. II. Phenolic compounds. Turrialba, San Jose, 24(2):217-221, 1974.

ARNON, D.l. Cooper enzymes in isolated chloroplasts. Polyphenoloxidases in Beta vulgaris. Plant Physiology, Palo Alto, 24:1, 1949.

BACCHI, O. O branqueamento dos grãos de café. Bragantia, Campinas, 21(28):467-484, 1962. 
BASSO, L.C.; AMORIM, H.V. \& CARVALHO, A. Polyamines content in different species and varieties of coffee. [Piracicaba, ESALQ, 1979] 1p. (Mimeografado)

CARELLI, M.L.C.; LOPES, C.R. \& MONACO, L.C. Chlorogenic acid content in species of Coffea and selections of Coffea arabica. Turrialba, San Jose, 24(4):398-401, 1974.

CARVALHO, A. \& KRUG, C.A. Genética de Coffea. Xll. Hereditariedade da cor amarela das sementes. Bragantia, Campinas, 9:193-203, 1949.

CHASSEVENT, F. XII Colloque Scientifique International sur le Café, Rapport de Synthèse - Agronomie. Café Cacao Thé, Paris, 31(3):219-221, 1987.

GIBSON, A. Photochemical aspects of East African Arabica Coffees. I. The importance of integument pigmentation. II. Raw bean colours produce from kahweol esters. In: COLLOQUE INTERNATIONAL SUR LE CAFÉ (ASIC), Paris, 1971. Resumés. p.246-258.

HARBORNE, J.B. Flavonoids: distribution and contribution to plant colour. In: GOODWIN, T.W., ed. Chemistry and Biochemistry of Plant Pigments. London, Academic Press, 1965. p.247-278.

- Methods of plant analysis. London, Chapman and Hall, 1973. p.1-32.

HARTMAN, L.; LAGO, R.C.A.; TANGO, J.S. \& TEIXEIRA, C.G. The effect of unsaponifiable matter on the properties of coffee seed oil. Journal of the American Oil Chemists' Society, Columbus, 45(8):577-579, 1968.

MELO, M.; FAZUOLI, L.C.; TEIXEIRA, A.A. \& AMORIM, H.V. Alteraçōes físicas, químicas e organolépticas em grãos de café armazenados. Ciência e Cultura, São Paulo, 32(4):468-471, 1980.

NORTHMORE, J.M. Raw bean colours and chlorogenic acid. In: SPECIALIST MEETING ON COFFEE RESEARCH IN EAST AFRICA, 1., Nairobi, 1966. Paper presented. p.326-331.

- Raw bean colours and the quality of Kenya Arabica Coffee. Turrialba, San Jose, 18(1):14-20, 1968.

- Some factors affecting the quality of Kenya coffee. Turrialba, San Jose, 15(3):184-193, 1965.

RIBEREAU-GAYON, P. Plant phenolics. Edinburg, Oliver and Boyd, 1972. 254p.

ROBINSON, J.B.D. Amber beans. Kenya Coffee, Nairobi, 25(291):91-93, 1960.

SEIKEL, M.K. Chromatography methods of separation, isolation and identification of flavonoids compounds. In: GEISSMAN, T.A., ed. The Chemistry and Biochemistry of Flavonoids Compounds. New York, The McMillan Company, 1962. p.34-69.

SMITH, R.F. Les acides chlorogéniques du café. Café Cacao Thé, Paris, 7(3):245-252, 1963.

SWAIN, T. Analytical methods for flavonoids. In: GOODWIN, T.W., ed. The Chemistry and Biochemistry of Plant Pigments. London, Academic Press, 1965 . p.533-549.

TEIXEIRA, A.A.; FAZUOLI, L.C. \& CARVALHO, A. Qualidade da bebida do café. Efeito do acondicionamento e do tempo de conservação. Bragantia, Campinas, 36(7):103-108, 1977.

WURZIGER, J. \& SUCHE, B. Chemical investigations to aid the supplementary quality evaluation of raw and roasted coffee beans. Relatório de análises enviado à Seçāo de Genética do Instituto Agronômico de Campinas. Campinas, 1983. 6p. (Mimeografado) 